УДК 343.98

\title{
А.М. Каминский, Д.А. Овчинникова
}

\section{ИСПОЛЬЗОВАНИЕ ЭЛЕКТРОННЫХ КРИМИНАЛИСТИЧЕСКИ НЕУПОРЯДОЧЕННЫХ БАНКОВ ДАННЫХ В РАСКРЫТИИ ПРЕСТУПЛЕНИЙ}

\begin{abstract}
В статье рассматриваются теоретические и практические вопросы использования в деятельности по выявлению, раскрытию и расследованию преступлений возможностей использования информации, содержащейся в электронных криминалистически неупорядоченных банках данных (ЭКНБД). В связи с этим исследуются основы формирующейся частной криминалистической теории информирования, возможности и принципы конструирования и создания криминалистических учетов, определяются их принципиальные отличия от ЭКНБД. Авторами предложены основы классификации ЭКНБД по возможности их использования в раскрытии корыстнонасильственных преступлений и преступлений, совершаемых в сфере экономики. На этой основе разработан и предложен алгоритм обращения следователей, оперативных работников и дознавателей к информации, содержащейся в ЭКНБД, а также правила работы с ней с учетом различных межведомственных документов, регулирующих этот процесс.
\end{abstract}

Ключевые слова: электронные криминалистически неорганизованные банки данных, деятельность по выявлению, раскрытию и расследованию преступлений, криминалистическая регистрация, криминалистические учеты.

DOI: $10.35634 / 2412-9593-2020-30-1-91-98$

Цифровизация общества наряду с положительными имеет и негативные стороны, такие как появление нового вида преступлений, ответственность за которые предусмотрена гл. 28 УК РФ, и расширение возможностей совершенствования преступных технологий, способов совершения «традиционных» видов преступлений.

Отсюда ясна потребность для практики раскрытия преступлений использования эффективных криминалистических методик борьбы с этими преступлениями. В этой сфере криминалистика достигла определенных результатов: «выявлен и исследован новый криминалистический объект - “кибернетическое пространство”, определяемый как среда совершения преступлений в сфере компьютерной информации и существования нового вида виртуальных следов» ${ }^{1}$. Плодотворно развивается новая частная криминалистическая теории информационно-компьютерного обеспечения криминалистической деятельности ${ }^{2}$. На наш взгляд, существует еще одно направление использования электронной информации в раскрытии преступлений, которое в теории криминалистики исследовано значительно меньше.

В условиях информатизации всех сфер жизнедеятельности субъекты общественных отношений, в том числе субъекты преступной деятельности (далее - ПД), оказываются вовлеченными в информационное общество, существуя и функционируя в условиях постоянного информационного обмена с окружающим миром. Каждое социально значимое действие субъекта влечет за собой не только появление информации, но и ее сохранение, накопление и систематизацию в составе различных учетов, имеющих вид информационных систем - основного инструментария информационных технологий.

Анализ эмпирического материала позволяет утверждать, что использование системы учетов, как криминалистических, так и криминалистически неупорядоченных, является одним из эффективнейших способов информационного обеспечения субъекта ДВРП в условиях недостаточности собственно следовой информации.

Вместе с тем изменившийся характер современной преступной деятельности позволяет сделать вывод о том, что она все чаще носит интеллектуальный характер, все больше внешне сходна с правомерной деятельностью, возрастающее количество экономических преступлений совершается именно под видом законной деятельности, законных хозяйственных операций. Следовательно, все больший объем криминалистически значимой информации может быть отражен в информационных системах некриминалистического характера.

\footnotetext{
${ }^{1}$ Мещеряков В.А. Основы методики расследования преступлений в сфере компьютерной информации: автореф. дис. ... докт. юрид. наук / Воронежский гос. ун-т. Воронеж, 2001. С. 9.

${ }^{2}$ Россинская Е.P. К вопросу о частной теории информационно-компьютерного обеспечения криминалистической деятельности // Известия Тульского гос. ун-та. Сер.: Экономические и юридические науки. Вып.3, ч. 2: Юридические науки. Тула: Изд-во Тульского гос. ун-та, 2016. С. 110.
} 
Проблема отражения информации, связанной с ПД субъекта, в криминалистически неупорядоченных банках данных, а также методика ее обнаружения, исследования и использования в деятельности по выявлению, раскрытию и расследованию преступлений (далее - ДВРП) на диссертационном уровне единственный раз была рассмотрена Г.А. Шкляевой ${ }^{3}$. Использование в целях информационного обеспечения субъектов ДВРП возможностей сложной системы электронных криминалистически неорганизованных банков данных (далее - ЭКНБД) и хранящейся в них электронной криминалистически значимой информации в научной литературе, за редким исключением ${ }^{4}$, не рассматривалось.

ЭКНБД в условиях компьютеризации и цифровизации общества приобрели форму автоматизированных, хранящих электронную информацию, информационно-техническую суть которых представляют автоматизированные банки данных. В настоящее время в России сложилась и функционирует сложная система ЭКНБД, которые служат удовлетворению информационных потребностей в самых различных предметных областях не только правоохранительных, но и любых других государственных органов власти, а также органов местного самоуправления, организаций и граждан. Хотя ЭКНБД не организованны в виде специальных криминалистических учетов, вместе с тем они содержат множество криминалистически значимой информации, которая может быть эффективно использована для разрешения криминалистических задач. Кроме того, большинство из них, следуя требованиям унификации информационных систем и расширения межведомственного взаимодействия, являются частью системы межведомственного электронного взаимодействия (СМЭВ), цель создания которой, в том числе, - обеспечение информационного взаимодействия в электронной форме между органами государственной власти, местного самоуправления, организациями и гражданами.

Обращение к ЭКНБД в целях информационного обеспечения субъектов ДВРП позволит им рационально использовать уже имеющуюся, систематизированную, криминалистически значимую информацию, осуществлять оптимальное и эффективное планирование своей деятельности, значительно сокращая сроки и повышая продуктивность поиска различного рода источников полезной информации, оказывая положительное влияние на организацию всей следственной деятельности.

Основным способом целевого взаимодействия как отдельного человека, так и всего социума с окружающим его материальным миром является деятельность ${ }^{5}$. Будучи формой и способом организации человеческой жизни, деятельность обусловила применение в целях разрешения задач криминалистики положений системно-деятельностного подхода, наиболее полно разработанного М.К. Каминским и являющегося на сегодняшний день общепризнанным ${ }^{6}$. С точки зрения данного подхода методологическими основами криминалистики выступают: 1) деятельность; 2) отражение как объективное свойство материи; 3) системность, то есть рассмотрение взаимодействия двух родов деятельности преступной и деятельности по выявлению, раскрытию и расследованию преступлений как единой системы, их связь; 4) след как единица анализа ${ }^{7}$.

Взаимосвязь, взаимозависимость ПД и ДВРП сторонники деятельностного подхода определяют в качестве двуединого объекта познания науки криминалистики. Напомним, что в качестве объекта науки понимают отдельные виды человеческой деятельности, являющиеся частью объективной реальности жизни общества и представляющие для криминалистики главный интерес. Конкретные аспекты (элементы) каждой такой деятельности, изучение которых может быть обеспечено средствами и методами криминалистики, составляют предмет криминалистики. Таковыми выступают закономерности механизма ПД; закономерности возникновения информации о преступлении и его участниках; закономерности процессов собирания, исследования, оценки и использования доказательств ${ }^{8}$

\footnotetext{
${ }^{3}$ Шкляева Г.А. Криминалистически неупорядоченные банки данных и их использование в деятельности по выявлению и раскрытию преступлений: дис. ... канд. юрид. наук. Ижевск, 1999.

${ }^{4}$ Хомяков Э.Г. Электронная медицинская карта как источник разыскной и криминалистически значимой информации при расследовании преступлений, связанных с безвестным исчезновением граждан // Раскрытие и расследование преступлений, связанных с безвестным исчезновением граждан: материалы междунар. науч.практ. конф. М.,2018. С. 223-226.

${ }^{5}$ Криминалистика: учебник / отв.ред. Н.П. Яблоков. 3-е изд. перераб. и доп. М.: Юристъ, 2005. С. 23.

${ }^{6}$ Протасевич А.А., Фойгель Е.И. Методология криминалистического учения о человеке и человеческой деятельности // Всероссийский криминологический журнал. 2017. Т. 11, № 3. С. 596.

${ }^{7}$ Каминский М.К. Что есть, что может быть и чего быть не может для системы «криминалистика» // Криминалистика, криминология и судебные экспертизы в свете системно-деятельностного подхода: науч.-практ. изд. Ижевск, 2001. Вып. 3. С. 7-8.

${ }^{8}$ Белкин Р.С. Криминалистика: проблемы, тенденции, перспективы. Общая и частная теории. М.: Юрид. лит., $1987.272 \mathrm{c}$
} 
Использование электронных криминалистически неупорядоченных банков данных...

Криминалистическая особенность изучения ПД состоит в том, что она исследуется не по отдельности, а во взаимосвязи с ДВРП. Исследуя эту взаимосвязь, необходимо выяснить, как именно две эти деятельности связаны между собой. Для ответа на этот вопрос следует отметить, что любая деятельность, в том числе ПД, оставляет за собой информацию. Вышеизложенное позволяет сделать вывод о том, что связь двух родов деятельности ПД и ДВРП носит информационный характер 9

Но что представляет собой информация? На наш взгляд, информация - есть мера изменения объекта. Так, объекты различных классов - человек, материальные объекты подвергаются воздействию со стороны субъекта ПД, индивидуального либо группового, который, реализуя свою преступную цель, преобразует исходные состояния этих объектов в конечные. В этих конечных состояниях объектов отражается информация о различных сторонах ПД: субъекте, его мотивах, целях, решаемых им задачах, об операционализмах (его действиях, операциях, движениях), о системе средств (технических и знаниевых), также об условиях (обстоятельствах), при которых происходило выполнение этих действий или реализовалась вся деятельность. Такого рода информацию принято называть следовой ${ }^{10}$.

Таким образом, ПД в ходе своего функционирования и развития отображает информацию о себе в измененных (преобразованных) состояниях объектов, на которые воздействовал субъект ПД. Положение о значимости этой информации, отраженной деятельностным событием преступления, для целей расследования преступления, было разработано теоретически и полностью подтверждено ходом практики.

Однако взаимодействие ПД и ДВРП не исчерпывается процессом отображения информации о ПД вовне. Существует и второй процесс отражательно-информационного характера, имеющий место в процессе выявления и раскрытия преступлений. По своему существу этот процесс представляет собой акт двойного отражения: со стороны ПД - отражение ее характеристики в измененных состояниях объектов, на которые воздействовал (непосредственно или опосредованно) субъект ПД; со стороны ДВРП - отражение отраженного, то есть информации, отраженной событием преступления во всякого рода взаимодействиях, сознанием субъекта ДВРП. Вопрос о том, как отраженная информация становится достоянием субъекта ДВРП, исследовался значительно меньше.

Субъект ДВРП может получить информацию о совершенном преступлении путем непосредственного восприятия определенных информационных следов, когда системы ПД и ДВРП взаимодействуют физически. Однако чаще всего непосредственное восприятие вследствие временных и пространных ограничений невозможно. В таком случае информация о прошедшем событии преступления, прошедших действиях субъектов преступной деятельности может стать доступной субъекту ДВРП лишь в результате обратного кодового преобразования ${ }^{11}$. Дело в том, что следовая информация, возникающая в процессе отражения ПД вовне, существует объективно, но лишь в потенциальной форме, то есть сама по себе она ни о чем не информирует.

Движение следовой информации в отражательном процессе осуществляется с помощью особых преобразований, которые следует называть кодовыми преобразованиями или кодами. В данном случае субъекту ДВРП необходимо, во-первых, обнаружить и зафиксировать эту информацию, во-вторых, для ее актуализации, то есть понимания содержания деятельностных процессов, породивших эту информацию, субъекту ДВРП необходимо выполнить особое преобразование - перекодировку, дешифровку, что может быть осуществлено либо физическими, либо мыслительными действиями. При выполнении всего комплекса этих действий субъект ДВРП будет способен воссоздать события минувшей ПД.

Таким образом, информационную связь между ПД и ДВРП обеспечивают не только информационные, но и кодовые преобразования. Процесс кодового преобразования следовой информации представляет собой процесс информирования. Информирование решает задачи связи и познания человеческой деятельности, это касается и ретроспективного познания, присутствующего при расследовании преступлений ${ }^{12}$.

\footnotetext{
${ }^{9}$ Мочагин П.В. О пяти механизмах следообразований, их кодах и информационном содержании // Вестн. Удм. ун-та. Сер.: Экономика и право. 2015. Т. 25, вып. 1. С. 187-196.

${ }^{10}$ Шкляева Г.А. Криминалистически неупорядоченные банки данных и их использование в деятельности по выявлению и раскрытию преступлений: дис. ...канд. юрид. наук. Ижевск, 1999. С. 20.

${ }^{11}$ Игнатьев М.Е. Категориальные понятия криминалистической теории причинности // Вестник Казанского юрид. ин-та МВД России. 2018. Т. 9, № 1. С. 93-102.

${ }^{12}$ Криминалистика: курс лекций для бакалавров / под ред. М.К. Каминского, А.М. Каминского. Ижевск: Jus est, 2012. C. 52.
} 
Таким образом, как верно отмечает Г.А. Шкляева, «с информационно-отражательной точки зрения ДВРП строится именно как процесс информирования» ${ }^{13}$.

В качестве примера проанализируем процесс информирования субъекта ДВРП, получившего сообщение о безвестном исчезновении человека в условиях неочевидности, который чаще всего характеризуется недостаточностью следовой информации. В результате анализа надлежит установить, с помощью каких средств и способов субъекты ДВРП восполняли недостаточность следовой информации.

При анализе 95 материалов проверок сообщений о преступлениях, связанных с безвестным исчезновением граждан, поступивших в один из следственных отделов г. Ижевска следственного управления Следственного комитета Российской Федерации по Удмуртской Республике, было установлено следующее. В 85 из исследуемых материалов лица, в отношении которых подавались заявления об исчезновении, были найдены и опрошены в течение 10 суток с момента поступления следователю сообщения. Большинство из них временно уходило из мест своего проживания по личным мотивам и возвращалось в течение нескольких дней. В рамках проверки сообщений о преступлениях, связанных с безвестным исчезновением, были проведены осмотры мест происшествий (проживания, последнего пребывания пропавших), опросы родственников и знакомых, пропавших. В отношении пропавших каких-либо преступлений и противоправных действий не совершалось, по результатам проверок были вынесены постановления об отказе в возбуждении уголовных дел по сообщениям о совершении преступлений, предусмотренных ст. 105 ч. 1, 126 ч. 1, 127 ч. 1 УК РФ, по факту безвестного исчезновения на основании п. 1 ч. 1 ст. 24 УПК РФ, за отсутствием событий указанных преступлений. В этих случаях субъект ДВРП располагал необходимой следовой и иной дополнительной информацией для принятия процессуального решения.

В иных случаях в течение 10 суток пропавшие на связь не выходили, в места своего проживания не возвращались, в результате проведения оперативно-разыскных мероприятий, процессуальных и следственных действий у субъектов ДВРП отсутствовала необходимая следовая информация для установления местонахождения пропавших, восстановления событий произошедшего и принятия законного, обоснованного и мотивированного процессуального решения по поступившему сообщению (о передаче сообщения о преступлении по подследственности (подсудности), об отказе в возбуждении уголовного дела или о возбуждении уголовного дела, принятии его к производству и дальнейшему расследованию).

Так, например, субъектом ДВРП было получено сообщение о преступлении, связанном с безвестным исчезновением мужчины 35 лет, который, согласно тексту заявления, покинул место своего проживания в вечернее время, чтобы прогуляться и отдохнуть, но домой не вернулся, на связь не выходил, куда именно и с кем он собирался пойти, не сообщал. В результате проведения проверочных мероприятий, осмотра места проживания, документов и предметов пропавшего, опросов родственников и знакомых, субъектом ДВРП было установлено наличие обстоятельств, свидетельствующих о признаках совершения преступления в отношении пропавшего, в том числе, перечисленных в Инструкции о порядке рассмотрения заявлений, сообщений о преступлениях и иной информации о происшествиях, связанных с безвестным исчезновением лиц, утвержденной совместным приказом МВД России № 38, Генпрокуратуры России № 14, СК России № 5 от 16.01.2015 ${ }^{14}$. Пропавший ранее не уходил, не высказывал намерений на долгое время куда-либо убыть или сменить место проживания, хронических заболеваний не имел, по месту проживания пропавшего оставались его личные документы - паспорт, пропуск на работу, некоторые из банковских карточек.

Вместе с тем, располагая информацией об обстоятельствах, свидетельствующих о том, что в отношении пропавшего могло быть совершено преступление, субъект ДВРП находился в ситуации недостаточности следовой информации для установления местонахождения пропавшего, обстоятельств произошедшего, восстановления модели преступной деятельности, которая, возможно, имела место, принятия соответствующего процессуального решения. В целях восполнения имеющихся информационных пробелов субъект ДВРП обратился к системе учетов криминалистически значимой информации.

\footnotetext{
${ }^{13}$ Шкляева Г.А. Криминалистически неупорядоченные банки данных и их использование в деятельности по выявлению и раскрытию преступлений: дис. ... канд. юрид. наук. Ижевск, 1999. С. 23.

${ }^{14}$ Приказ МВД России № 38, Генпрокуратуры России № 14, СК России № 5 от 16.01.2015 «Об утверждении Инструкции о порядке рассмотрения заявлений, сообщений о преступлениях и иной информации о происшествиях, связанных с безвестным исчезновением лиц» (Зарегистрировано в Минюсте России 20.03 .2015 № 36499) // Официальный интернет-портал правовой информации. URL: http://www.pravo.gov.ru (дата обращения: 23.03.2015).
} 
Использование электронных криминалистически неупорядоченных банков данных...

По поручению следователя были проведены оперативно-разыскные мероприятия, в том числе по проверке сведений по информационным базам данных (оперативным учетам) «Магистраль» и «Авиа», в результате которой было установлено, что пропавший пределы Удмуртской Республики не покидал, в других субъектах РФ замечен не был.

Субъект ДВРП обратился к системе ведомственных, в том числе электронных учетов, осуществив следующие запросы: в учреждения уголовно-исполнительной системы (ИВС МВД по УР, ФКУ СИЗО - 1 УФСИН России по Удмуртской Республике); в медицинские учреждения (МСЧ № 7, МСЧ № 3, РКБ № 1, ГКБ № 3, РНД, РКПБ), а также в иные частные учреждения. Положительной информации о местонахождении пропавшего в указанных учреждениях найдено не было. Также был осуществлен мониторинг сайтов сети «Интернет» социальной сети «ВКонтакте» с целью установления личной страницы пропавшего, в результате чего было установлено, что пропавший последний раз появлялся в сети в день исчезновения в 22 часа.

Субъект ДВРП обратился к учетам коммерческой организации по месту работы пропавшего, в том числе к электронным. Субъектом ДВРП было истребовано личное дело пропавшего, у сотрудников службы безопасности организации запрошен электронный журнал пропускной системы, проведены опросы работников.

В результате обобщения и анализа полученной информации было установлено, что после своего исчезновения пропавший больше не появлялся на работе, не выходил на связь и не появлялся в сети «Интернет», знакомыми, родственниками и иными лицами замечен не был, в каких-либо учреждениях не числился. По истечении 30 дней было принято решение о возбуждении уголовного дела по признакам преступлений, предусмотренных ст. 105 ч. 1, 126 ч. 1, 127 ч. 1 УК РФ, по факту безвестного исчезновения гражданина.

В рамках уголовного дела, с соблюдением соответствующего процессуального порядка субъект ДВРП обратился к ведомственным учетам налогового органа, была запрошена информация об открытых на имя пропавшего расчетных счетах в банках и иных кредитных организациях. После чего были осуществлены запросы в соответствующие кредитные организации об открытых лицевых счетах, о движении денежных средств по данным счетам, с указанием назначений платежей, респондентов, оснований зачисления денежных средств на счета и их списания (снятия через банкоматы). На основании полученной информации были изъяты записи видеокамер из банкомата, в котором пропавший в вечер своего исчезновения последний раз осуществлял снятие денежных средств. Видеозапись позволила установить, что пропавший приехал и уехал от банкомата на автомобиле. По результатам запроса сведений из архива аппаратно-программного комплекса «Безопасный город» и ведомственной базы данных Управления ГИБДД МВД по Удмуртской Республике была получена информация о собственнике транспортного средства, на котором передвигался в день своего исчезновения пропавший, а также установлен маршрут движения автомобиля. Проведенные на основании полученной из вышеуказанных учётов информации следственные и процессуальные и действия, в том числе осмотр местности, транспортного средства, допрос его владельца, позволили установить местонахождение трупа пропавшего, причастных лиц, воссоздать модель преступной деятельности.

Таким образом, поиск информации в ЭКНБД основывается на принципе взаимосвязи и взаимозависимости следовой и дополнительной информации. Криминалистический анализ следовой информации, имеющийся в распоряжении субъекта ДВРП, может и должен позволить обоснованно прогнозировать связь этой информации с информацией в ЭКНБД.

Поэтому в условиях недостаточности следовой информации у субъекта ДВРП, поиск криминалистически значимой информации может быть осуществлен посредством обращения к ЭКНБД, с соблюдением определенного алгоритма. С точки зрения А.С. Шаталова, криминалистический алгоритм правило, сформулированное при помощи понятийного аппарата (языка) и научных рекомендаций криминалистики, определяющее процесс переработки субъектом расследования исходных данных в искомые результаты ${ }^{15}$. Алгоритм действий лица должен обеспечивать оптимальное использование процессуальных сроков в условиях информационного и временного дефицита. Алгоритм обращения субъекта ДВРП к ЭКНБД в целях осуществления поиска криминалистически значимой информации и построения ДВРП с ее использованием можно представить следующим образом.

\footnotetext{
15 Шаталов А.С. Криминалистические алгоритмы и программы. Теория. Проблемы. Прикладные аспекты.
} M., 2000. $252 \mathrm{c}$. 
1. Выявить и проанализировать имеющуюся следовую информацию.

2. Обосновать перечень дополнительной (связанной со следовой) информации, необходимой для расследования.

\section{$\downarrow$ \\ 3. Определить тип искомой информации.

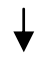 \\ 4. Определить соответствующий, хранящий искомую информацию банк данных.}

5. Определить форму запроса и порядок получения информации из банка данных; запросы подвергаются терминологической обработке с помощью информационно-текстового языка, составляются с использованием всей информации, чтобы максимально сузить зону поиска.

6. Осуществить извлечение криминалистически значимой информации из банка данных.

7. Определить порядок процессуальной трансформации (приобщения) полученных сведений к материалам дела.

\section{$\downarrow$}

8. Приобщить и использовать полученные сведения в расследовании преступления

Реализация алгоритма обращения субъекта ДВРП к ЭКНБД в целях поиска следовой и иной криминалистически значимой информации невозможна без познания содержания существующих ЭКНБД. Предлагаемый алгоритм носит универсальный характер, но для его эффективного использования можно выделить ЭКНБД, содержащие информацию, криминалистически значимую для осуществления ДВРП экономической направленности, разделив их на соответствующие подвиды:

1) ЭКНБД, содержащие криминалистически значимую информацию для осуществления ДВРП в сфере незаконного банкротства;

2) ЭКНБД, содержащие криминалистически значимую информацию для осуществления деятельности по выявлению, раскрытию и расследованию налоговых преступлений.

Однако не стоит оставлять без внимания возможность использования в ДВРП насильственного характера ЭКНБД, в первую очередь медицинских.

Одной из задач деятельности Министерства здравоохранения России является создание единого цифрового контура в здравоохранении на основе единой государственной информационной системы в сфере здравоохранения (ЕГИСЗ), концепция и основные этапы создания которой были утверждены еще в 2011 г. $^{16}$

Помимо медицинских, в ДВРП различных групп, в том числе насильственных, достаточно часто используются данные Единого государственного реестра недвижимости (ЕГРН) - этого достоверного источника информации об объектах недвижимости на территории Российской Федерации, администратором которого является Федеральная служба государственной регистрации, кадастра и картографии (Росреестр). ЕГРН представляет собой свод достоверных систематизированных сведений в текстовой форме (семантические сведения) и графической форме (графические сведения) и состоит из реестра объектов недвижимости (кадастр недвижимости); реестра прав, ограничений прав и обременений недвижимого имущества (реестр прав на недвижимость); реестра сведений о границах зон с особыми условиями использования территорий; реестровых дел; кадастровых карт; книг учета документов.

Возвращаясь к необходимости наложения ареста в ходе осуществления ДВРП насильственных и иных групп, следует упомянуть и автоматизированную информационную систему ФССП России.

Способствуют осуществлению эффективной ДВРП различных групп, в том числе насильственных, также ресурсы криминалистически неупорядоченной единой информационной системы миграционной службы: автоматизированной системы центрального банка данных по учету иностранных

\footnotetext{
${ }^{16}$ Приказ Минздравсоцразвития России от 28.04.2011 № 364 (ред. от 12.04.2012) «Об утверждении Концепции создания единой государственной информационной системы в сфере здравоохранения» // СПС «КонсультантПлюс».
} 
граждан и лиц без гражданства, временно пребывающих и временно или постоянно проживающих в Российской Федерации ${ }^{17}$.

Изложенный материал позволяет сделать некоторые выводы и определить следующие направления развития в сфере применения ЭКНБД в ДВРП:

- во-первых, применение ЭКНБД в ДВРП имеет серьезные перспективы: использование возможностей ЭКНБД в целях информационного обеспечения субъектов ДВРП позволит последним наиболее рационально использовать уже имеющуюся, систематизированную криминалистически значимую информацию, осуществлять оптимальное и эффективное планирование своей деятельности, сокращая сроки и повышая продуктивность поиска различного рода источников полезной информации, в целом оказывая положительное влияние на организацию следственной деятельности;

- во-вторых, для реализации такого перспективного направления, как использование ЭКНБД в ДВРП, необходимо соответствующее научное, учебно-методическое, нормативное и иное обеспечение. Анализ современной учебной литературы по криминалистике позволяет сделать вывод о необходимости ее актуализации в части обновления рекомендаций по работе со следовой информацией, имеющей цифровой вид, исследования возможностей современных АИС, в том числе некриминалистического характера (ЭКНБД). Такая обусловленная потребностями практики необходимость породила в научных кругах дискуссию о возможности выделения новой формирующейся частной криминалистической теории электронной (цифровой) криминалистики, которая, на наш взгляд, действительно нуждается в выделении и «внедрении» в учебную литературу. Существующее нормативное обеспечение информационного взаимодействия и регламентация процесса обмена информацией в электронной форме между правоохранительными и иными органами государственной власти, местного самоуправления, организациями и гражданами также имеет некоторые пробелы, требующие соответствующего устранения.

Таким образом, в условиях информатизации и цифровизации общества, унификации информационных систем, криминалистические задачи могут и решаются посредством использования информации, хранящейся в ЭКНБД. Вместе с тем существующее научное, учебно-методическое, нормативное и иное обеспечение нуждается в определенной доработке с целью наиболее эффективного использования ЭКНБД в ДВРП.

Поступила в редакцию 22.12.2019

Каминский Александр Маратович, доктор юридических наук, профессор, заведующий кафедрой криминалистики и судебных экспертиз

ФГБОУ ВО «Удмуртский государственный университет»

426034, Россия, г. Ижевск, ул. Университетская, 1 (корп. 4)

E-mail: kam2090@yandex.ru

Овчинникова Диляра Александровна, старший консультант отдела судебной защиты

Управления правовой работы с дебиторской задолженностью регионального центра правового обеспечения в г. Ижевске ПАО «Т Плюс»

426051, Россия, г. Ижевск, проезд Дерябина, 7

E-mail: kam2090@yandex.ru

\section{A.M. Kaminsky, D.A. Ovchinnikova} USE OF ELECTRONIC FORENSICALLY DISORDERED DATA BANKS IN CRIME DISCLOSURE

DOI: $10.35634 / 2412-9593-2020-30-1-91-98$

The article discusses the theoretical and practical issues of using the information contained in electronic forensically disordered data banks (EFDDB) for identifying, disclosing and investigating crimes. In this regard, the basics of the emerging private forensic theory of information, the possibilities and principles of the design and creation of forensic

\footnotetext{
${ }^{17}$ Приказ МВД РФ от 03.07.2006 № 518 «Об утверждении Инструкции по формированию, ведению и использованию центрального банка данных по учету иностранных граждан и лиц без гражданства, временно пребывающих и временно или постоянно проживающих на территории субъектов Российской Федерации, в территориальных органах ФМС России и МВД, ГУВД, УВД субъектов Российской Федерации» // СПС «КонсультантПлюс».
} 
records are examined, their fundamental differences from the EFDDB are determined. The authors proposed the basis for the classification of EFDDB for the possibility of their use in the disclosure of mercenary-violent crimes and crimes committed in the economic sphere. On this basis, an algorithm has been developed and proposed to appeal to investigators, operating executives and interrogators about the information contained in the EFDDB, as well as the rules for working with it, taking into account various interdepartmental documents regulating this process.

Keywords: electronic forensically disordered databanks, activities for the detection, disclosure and investigation of crimes, forensic registration, forensic records.

Received 22.12.2019

Kaminsky A.M., Doctor of Law, Professor, Head of the Department of Forensics and Forensics

Udmurt State University

Universitetskaya st., 1/4, Izhevsk, Russia, 426034

E-mail:kam2090@yandex.ru

Ovchinnikova D.A., Senior Bankruptcy Consultant, Legal Protection Division, Office of Legal Work with Receivables of the Regional Legal Support Center in Izhevsk, P Plus

Deryabina st., 7, Izhevsk, Russia, 426051

E-mail:kam2090@yandex.ru 